Maja Biernacka

Katedra Socjologit Wielokulturowości

INSTYTUT SOCJOLOGII I KogNityWISTYKi

UNIWERSYTET W BIAŁYMSTOKU

MMBIERNACKA@TLEN.PL

\title{
BYĆ BASKIEM, CZYLI O RELACJI MIĘDZY EUSKERA A TOŻSAMOŚCIĄ
}

\section{Wprowadzenie}

Konwencjonalne wyobrażenia na temat Basków w Hiszpanii są budowane przez negację. Chodzi mianowicie o arbitralne stawianie baskijskości w dychotomii względem hiszpańskiej kultury większościowej podpartej ideą jednego narodu, w której są zasklepieni wbrew własnej woli w granicach jednego państwa․ Choć wśród nich jest obecna chęć odłączenia się od Hiszpanii, dotyczy ona jedynie pewnej części baskijskiej populacji. Co więcej, nie jest prawdą, jakoby tożsamość baskijska łączyła wszystkich mieszkańców regionu i była w sposób jednoznaczny kolizyjna względem hiszpańskiej. Kwestię szeroko rozumianej tożsamości baskijskiej, zwłaszcza tożsamości podwójnych oraz złożonych², a także tendencji separatystycznych oraz faktycznych

1 Szczegółowo na temat kształtowania się idei narodowej w Hiszpanii patrz: M. Biernacka, La hispanidad. Idea prymatu narodu hiszpańskiego, „Studia Socjologiczne” 2009, nr 3 (194): 109-134.

2 Jak konsekwentnie pokazują dane sondażowe, tożsamość baskijska i hiszpańska nie są traktowane przez samych mieszkańców Autonomii Kraju Basków jako w sposób konieczny rozłączne i spory odsetek wyraża podwójną identyfikację. Istnieje jednak ogólna tendencja do poczucia silniejszej identyfikacji baskijskiej niż hiszpańskiej wśród tych, którzy deklarują tożsamości podwójne. Niewielki jest wśród mieszkańców tej autonomii odsetek respondentów, którzy czują się wyłącznie Hiszpanami, a odrzucają baskijskość - oscyluje on w kolejnych sondażach każdorazowo na poziomie kilku procent. $Z$ drugiej strony, znaczący odsetek badanych, to jest aż około jedna trzecia całej próby, identyfikuje się tak samo silnie z Hiszpanią, jak i z regionem. Rozkład danych uwiarygodnia ich powtarzalność w kolejnych sondażach: rozpoczynam od najnowszego, tj. Euskobarómetro ze stycznia 2016 r. (s. 61, wykres 31), wcześniejszego - z maja 2015 r. (s. 56, wykres 26) oraz z tego samego okresu w poprzednich kilku latach: z maja 2014 r. (s. 52, wykres 26), otrzymanych 
możliwości ewentualnej secesji planuję poddać analizie w odrębnych artykułach, podobnie jak zagadnienia dotyczące polityki językowej w Hiszpanii wraz z jej przemianami, o których nie należy pisać pobieżnie. Ten dotyczy związków tożsamości z językiem baskijskim, czyli euskera, ponieważ właśnie to on jest kardynalnym wyróżnikiem symbolicznym baskijskości.

Analiza prowadzona przez pryzmat języka jako elementu tożsamości zbiorowej pozwala przełamać esencjalistyczną konwencję, jaką jest kategoryzowanie Basków w prostej kontrze względem Hiszpanów i zakreślanie jej według mapy regionu. W ramach tego artykułu ograniczam się do terenów Autonomii Kraju Basków, co przede wszystkim ma znaczenie w odniesieniu do szczegółowych danych sondażowych dotyczących znajomości języka baskijskiego względem kastylijskiego. Ograniczenie geograficzne wprowadzam z dwóch przyczyn. Po pierwsze, istnieją znaczące różnice $\mathrm{w}$ zakresie tożsamości, i zarazem znajomości języka między mieszkańcami tej wspólnoty autonomicznej a Autonomią Nawarry, gdzie jest on również w użyciu, a także frankofońską częścią historycznej krainy Baskonii. Po drugie, odmienna jest legislacja oraz polityka językowa na każdym z tych obszarów i fakt ten nie pozostaje bez wpływu na miejsce języka baskijskiego w życiu społecznym. Po trzecie, istnieją spore różnice w zakresie zarówno tożsamości, jak i języka między poszczególnymi prowincjami Autonomii Kraju Basków, a nawet w ich obrębie. Dlatego właśnie, kierując się celem dbałości o szczegół i zachowania porządku argumentacji, pozostawiam rzeczywistość społeczną terenów mieszczących się poza tą Autonomią w kontekście baskijskości a conto kolejnej pracy.

\section{Euskera jako scheda praprzodków}

Język baskijski, którego nazwa własna to euskera ${ }^{3}$, jest jedynym językiem mniejszościowym ${ }^{4}$ w Hiszpanii, który jest dla pozostałych oby-

dokładnie rok wcześniej w ramach Euskobarómetro z maja 2013 r. (s. 50, wykres 23) oraz dwa lata wcześniej, tj. z maja 2012 r. (s. 46, wykres 21).

3 Obok euskera istnieją też wersje nazwy tego języka jako: euskara, eskuara, eskuora czy też üskara. Istnieją różne dialekty w obrębie tego języka, stąd oboczność jego nazwy własnej. W celu zachowania spójności posługuję się w artykule pierwszą z nich zamiennie względem zrozumiałego dla nie-specjalistów, zatem będącego na co dzień w użyciu, opisowego określenia język baskijski.

4 Zgodnie ze Statutem Wspólnoty Autonomicznej Kraju Basków (Ley Orgánica 3/1979), euskera uznany jest jako język własny tak zwanego w jego treści Ludu Basków (orig. Pueblo Vasco) i ma, 
wateli kraju całkowicie niezrozumiały, chyba że - co nie zdarza się często - podjęli wysiłek jego poznania. Jest to zadanie trudne zwłaszcza, że nie należy on do grupy języków romańskich, ani nawet rodziny języków indoeuropejskich, w przeciwieństwie - co dotyczy obu tych kryteriów - przyjętego jako oficjalny na poziomie ogólnopaństwowym języka kastylijskiego, zwyczajowo zwanego hiszpańskim, a także innych języków mniejszościowych, choćby katalońskiego czy galisyjskiego. Poza nielicznymi wyrazami o proweniencji łacińskiej i paru współcześnie używanych języków ${ }^{5}$, co czytelne jest dla analizujących je specjalistów, próżno szukać względem nich podobieństw w baskijskim, które pozwoliłyby znajdować sens oraz nawiązywać skuteczną komunikację bez jego faktycznej znajomości. Odmienność euskera jest ważna nie tylko w kategoriach lingwistycznych, ale również kształtowania oraz podtrzymywania baskijskości. Zapewnia możliwość odniesienia do przeszłości i projekcji własnej tożsamości wstecz nie jedynie poprzez - jak pozwolę sobie to nazwać - archeologizację wspólnych korzeni, to jest odniesienie do tego, co istniało w przeszłości i zaginęło bezpowrotnie. Dzieje sie to w sposób jak najbardziej namacalny - to jest przez euskera, który w dalszym ciągu pozostaje językiem żywym.

obok kastylijskiego, status języka oficjalnego w Kraju Basków (art. 6.1). Wszyscy jego mieszkańcy mają prawo znać i posługiwać się tymi obydwoma językami (art. 6.1). Prawo to gwarantowane jest oraz podlega regulacjom ze strony instytucji publicznych Wspólnoty Kraju Basków, które odpowiadają również za sposoby oraz środki mające na celu zapewnienie jego znajomości (art. 6.2). Co więcej, Statut stanowi, że nikt nie może być dyskryminowany ze względu na język (art. 6.3).

5 Kilka przykładów takich wyrazów podaje Estibaliz Amorrortu [2003: 12, tab.1.1] za: S. Segura i J. M. Etxebarria (1996), np. aingerua (od łac. angelus 'anioł'), ortua (od łac. hortus 'ogród'). Istnieją również zapożyczenia z języka hiszpańskiego, francuskiego, a także angielskiego. Jeśli chodzi o ten ostatni związane są one z zabiegami adaptacji baskijskiego do świata współczesnego, np. traka (od ang. truck 'ciężarówka'), aiskrimia (od ang. icecream 'lody') [Segura, Etxebarria 1996: 37] w tym również nowych technologii. Są to jednak pojedyncze zapożyczenia leksykalne, a gramatyka, w tym składnia, fleksja tego języka są na tyle odmienne, że baskijski pozostaje całkowicie niezrozumiały dla osób, które się go nie uczyły. 
Maja Biernacka

\section{Euskaldunak versus erdaldunak, czyli o baskijskim atrybucie językowym w danych statystycznych dotyczących Autonomii Kraju Basków}

Euskera ma status jednego spośród języków urzędowych w Hiszpanii, oczywiście nie na poziomie centralnym, ale autonomicznym ${ }^{6}$. Wbrew potocznym wyobrażeniom - jest on również dla znaczącego odsetka mieszkańców Autonomii Kraju Basków niezrozumiały. Język ten nie stanowi czynnika spajającego mieszkańców regionu z uwagi na prozaiczny fakt, że nie wszyscy się nim posługują, a raczej wyróżnik symboliczny baskijskości i sposób weryfikacji jej autentyczności. Dotyczy to nie tylko imigrantów, których zgodnie z ostatnio uzyskanymi danymi było $6,6 \%{ }^{7}$ populacji Autonomii Kraju Basków [ES 2013: 64], ale również rdzennych mieszkańców. Na określenie tych, którzy się nim posługują oraz tych, którzy go nie znają stosuje się endoetnonimy - odpowiednio: euskaldunak i eraldunak.

Należy poczynić zastrzeżenie, że w próbie mogli znaleźć się nie tylko imigranci, ale również ludność napływowa z pozostałych regionów Hiszpanii, z racji swego braku zakorzenienia kulturowego nie znająca, ewentualnie ucząca się euskera. Poniżej przedstawiam dane sondażowe dotyczące znajomości euskera, uzyskane na reprezentatywnej próbie Autonomii Kraju Basków w celu pokazania skali zjawiska. Najnowsze dane w tym zakresie opublikowane w 2013 r. [ES 2013, ryc. 4: 67], wcześniej zbierane były w przeprowadzonym w ramach tego samego projektu sondażu w roku 2008 [IV ES 2008, ryc. 3: 18$]^{8}$. Dodatkowo interesujący jest fakt, że dane zbierane i analizowane były według poszczególnych prowincji Autonomii Kraju Basków. Składają się na

6 Dotyczy to Autonomii Kraju Basków, w której ma on taki status obok kastylijskiego (więcej przypis 4), a także administracyjnie wyznaczonych stref północnej części Autonomii Nawarry, która ma zupełnie inne zasady legislacyjne.

7 Jest to odsetek imigrantów dwukrotnie mniejszy w porównaniu ze średnią w całej Hiszpanii. Większość przybyszy osiedla się w największych aglomeracjach, zwłaszcza Madrytu i Barcelony, a także ramowo mówiąc - nadmorskim pasie południa Hiszpanii.

8 Dane surowe zbierane były odpowiednio w latach 2011 i 2006. Zestawiam dane z tych dwóch okresów w celu pokazania, że proporcje dotyczące znajomości euskera w poszczególnych prowincjach mają charakter stabilny. Nie sięgam w tym artykule do wcześniejszych okresów, ponieważ wymagałoby to skupienia się na przemianach w zakresie statusu euskera w społeczeństwie, a również zmian legislacyjnych dotyczących języka w Hiszpanii oraz polityki etnicznej i językowej. Problemy te poddam analizie w kolejnym artykule. 
nią trzy prowincje: Álava, Guipúzcoa i Vizcaya9 ${ }^{9}$ Na podstawie art.2 obowiązującego do dnia dzisiejszego Statutu Autonomii Kraju Basków [Ley Orgánica 3/1979], znanego powszechnie pod nazwą Statutu z Guerniki, przystąpiły one w trybie transformacji systemowej do stworzenia Autonomii Kraju Basków w ramach państwa hiszpańskiego. Legislacyjną możliwość dołączenia stworzono również dla Nawarry, w której jednak nie było wystarczającej woli politycznej dla inkorporacji w ramach Autonomii Kraju Basków. W trybie konsensusu politycznego stała się ona odrębną wspólnotą autonomiczną.

Nie bez znaczenia jeśli chodzi o baskijską tożsamość jest fakt, że kompetencje językowe mieszkańców są bardzo zróżnicowane geograficznie nawet w obrębie Autonomii. Dane dotyczące różnic między prowincjami przedstawiam poniżej zgodnie z tabelami [V ES 2013, ryc. 5: 69; IV ES 2008, ryc. 4: 18]. Zagregowane dane zaprezentowane będą dalej wraz z odpowiednim odnośnikiem.

Mianowicie, w prowincji Guipúzcoa w 2011 r. językiem baskijskim posługiwało się 49,9\% \%, w 2006 r. - 49,1\%, to jest niemal połowa respondentów kwalifikowała się jako euskaldunak. Dodatkowo, tak zwanych osób pasywnie dwujęzycznych ${ }^{10}$ było w 2011 r. 16,4\%, w 2006 r. - 15,9\%. Co interesujące, około jednej trzeciej respondentów, tj. 33,7\% przyznało w 2011 r., że nie zna języka baskijskiego ${ }^{11}$, czyli jest erdaldunak - podczas gdy $\mathrm{w}$ sondażu przeprowadzonym pięć lat wcześniej ich odsetek wyniósł 35\%. W prowincji Vizcaya językiem baskijskim posługiwał się mniej więcej co czwarty badany: w 2011 r. było to 25,4\%, a w 2006 r. 23\%. Osób pasywnie dwujęzycznych było w 2011 r. - 17,8\%, a w 2006 r.

9 Konsekwentnie posługuję się w tekście powszechnie stosowaną kastylijską nazwą każdej z nich. Dla porządku podaję dodatkowo ich nazwy w euskera, jedynie nieco odmienne, odpowiednio: Araba, Bizkaia oraz Gipuzkoa.

10 W dzisiejszej Hiszpanii dwujęzyczność pasywna oznacza zdecydowanie częściej w kontekście baskijskim płynną znajomość języka kastylijskiego, a pasywną - euskera.

11 Zakwalifikowani są przez autorów sondażu jako monolingües erdaldunes, co stanowi zbitkę dwóch wyrazów, pierwszy z nich jest przymiotnikiem w języku kastylijskim i opisuje osoby znające tylko jeden język, tj. jednojęzycznej, a drugi jest rzeczownikiem w języku baskijskim, zaadaptowanym do hiszpańskiego tekstu cytowanego sondażu przez końcówkę liczby mnogiej (-es) i dotyczy osób posługujących się innym językiem niż baskijski, czyli erdaldun - w ślad za tym, co zostało wyjaśnione wcześniej w tekście. Abstrahując od użycia pierwszego wyrazu w języku kastylijskim, poprawną - choć mniej czytelną dla czytelnika tekstów w języku hiszpańskim oraz angielskim - formą drugiego byłoby erdaldunak. Podobnie, dodanie końcówki -es do wyrazów euskaldun i erdaldun dla oznaczenia liczby mnogiej pojawia się niekiedy w literaturze w języku angielskim o tematyce baskijskiej. Dotyczy to również prac cytowanych w tym tekście, oczywiście poza podręcznikami i słownikami języka euskera, które zachowują rygor słowotwórczy. 
- 19,4\%. Co interesujące, aż ponad połowa respondentów z tej prowincji, tj. 56,8 \% przyznała w 2011 r., że nie zna języka baskijskiego. W 2006 r. ich odsetek wyniósł $57,7 \%$. W prowincji Álava znajomość języka baskijskiego deklarowało znacznie mniej badanych: w 2011 r. - 16,8\%, w 2006 r. 14,2\%. Osób pasywnie dwujęzycznych było w 2011 r. - 16,8\%, a w 2006 r. - 20\%. Zdecydowanie ponad połowa respondentów, tj. 66,4\% przyznała w 2011 r., że nie zna języka baskijskiego. W 2006 r. osób deklarujących brak znajomości języka baskijskiego było 65,8\%.

Zgodnie z zagregowanymi danymi z dwóch okresów, w których przeprowadzony był sondaż: w 2011 r. [V ES 2013, ryc. 4: 66] oraz w roku 2006 [IV ES 2008, ryc. 3: 18], ogólnie rzecz biorąc nieco mniej niż co trzeci mieszkaniec Autonomii jest w stanie posługiwać się językiem baskijskim obok kastylijskiego, w 2011 r. było to 32\%, a w 2006 r. - 30,1\%. Część respondentów deklarowała, że ich dwujęzyczność ma charakter pasywny. W 2011 r. w taki sposób oceniło swe umiejętności językowe 17,4 \%, a w 2006 r. - 18,3\%. Co interesujące, ponad połowa respondentów, tj. 50,6\%, przyznała w 2011 r., że nie zna języka baskijskiego. W 2006 r. ich odsetek wyniósł 51,5\%.

Choć Autonomia Kraju Basków uznawana jest za serce hiszpańskiej części historycznej krainy Baskonii, jedynie część jej mieszkańców jest w stanie posługiwać się językiem baskijskim. Warto zwrócić uwagę na fakt, że istnieją zasadnicze różnice dotyczące kompetencji językowych w poszczególnych prowincjach. Jak pokazują szczegółowe dane, największy odsetek euskaldunak mieszka w Guipúzcoa, zdecydowanie mniejszy jest w Vizcaya, a jeszcze nieco mniejszy w prowincji Álava. Prowincja Guipúzcoa uchodzi za tę, którą charakteryzuje najwyższy poziom poczucia odrębności od Hiszpanii w zakresie zarówno samoookreślenia jej mieszkańców, jak i aspiracji separatystycznych. Na drugim miejscu jest w tych zakresach Vizcaya, choć pewnym zaskoczeniem może być tak znacząca różnica w zakresie znajomości euskera między tymi dwiema prowincjami. A mianowicie, są to dwie prowincje, które uważane są za podporę działań na rzecz secesji w sensie działań politycznych, a także poparcia społecznego. W prowincji Álava tradycyjnie poziom tożsamości baskijskiej, jak też chęci odłączenia się nie był aż tak wysoki. Widoczne jest to nawet w pamięci historycznej na temat regionu. Podczas, gdy w okresie Wojny Domowej w prowincjach Guipúzcoa i Vizcaya opór wobec nowo rodzącego się reżimu był znaczący i zostały one uznane przez generała Franco za provincias traidoras, czyli zdradzieckie prowincje, w prowincji Álava sytuacja była nie tylko w znacznie mniejszym stopniu zaogniona, ale i dominowały postawy kompromisu wobec reżimu. 
Zaowocowało to łagodniejszym jej traktowaniem przez władze centralne przez okres trwania frankizmu. Już po śmierci Franco w czasach transformacji systemowej końca lat siedemdziesiątych XX w., gdy wykształciła się formuła państwa hiszpańskiego opartego na istnieniu wspólnot autonomicznych, stolicę tejże prowincji, tj. Vitoria-Gasteiz, ustanowiono zarazem miastem stołecznym całej wspólnoty autonomicznej Kraju Basków. Wobec relatywnie słabego - względem prowincji Guipúzcoa i Vizcaya - poziomu poczucia odrębności wśród jej mieszkańców, decyzja polityczna o skupieniu władzy na poziomie autonomicznym w prowincji Álava była najbezpieczniejsza z perspektywy pragmatycznych interesów władzy centralnej oraz monarchii, nie kładąc się cieniem zdradzieckości względem Hiszpanii, jak byłoby to w przypadku pozostałych dwóch. Można byłoby stawiać tezę, że różnice $\mathrm{w}$ zakresie danych dotyczących znajomości euskera stanowią odzwierciedlenie odmienności między tymi prowincjami w zakresie historycznie uwarunkowanej tożsamości oraz poczucia odrębności. Nie bez znaczenia pozostaje także fakt przemieszczania się ludności, który sprawił, że granice wspólnot etnicznych stopniowo zacierały się.

\section{Pozostałe atrybuty baskijskości i ich słaba moc}

Poza językiem istnieją oczywiście komplementarne atrybuty związane $\mathrm{z}$ baskijskością. Istotną kwestią jest fakt urodzenia na baskońskich terenach oraz posiadania baskijskich rodziców, a także baskijskie imię i nazwisko. Sprawa baskijskiej tożsamości jest o tyle skomplikowana, że jedynie część mieszkańców regionu czuje się związana z przeszłością tej wspólnoty etnicznej. Liczne były $\mathrm{z}$ jednej strony napływy ludności na tereny Kraju Basków [więcej np. w: Luxán, 2005], a drugiej strony fale emigracyjne z terenów Baskonii do innych regionów Hiszpanii, do krajów Europy Zachodniej, a również na tereny Nowego Kontynentu [Mathy, 1997], co sprawia, że tożsamości wielu mieszkańców Kraju Basków mają charakter złożony. Dodatkowym czynnikiem takiego stanu rzeczy jest fakt mieszania się ludności rdzennej przez małżeństwa, w związku z czym z pokolenia na pokolenie coraz bardziej zacierają się granice wspólnoty etnicznej. Choć charakterystyczne nazwiska wskazują na istnienie tamtejszych korzeni, również nie stanowią jednoznacznego dowodu na baskijską tożsamość. Po pierwsze, są one zasadniczo, tak jak i pozostałych regionach Hiszpanii, dwuczłonowe i jeden człon może być baskijski, a drugi kastylijski, a po drugie, dziedziczone po przodkach nazwisko niekoniecznie idzie $\mathrm{w}$ parze $\mathrm{z}$ tożsamością. $\mathrm{W}$ związku z przemieszczaniem 
się ludności ${ }^{12}$ i zawieraniem małżeństw z przedstawicielami innych grup etnicznych, baskijskie nazwiska noszą w Hiszpanii oraz innych kontynentach - wskutek migracji - zarówno osoby o tożsamości baskijskiej jak i takie, które nie określają samych siebie jako Basków i z których część ma jedynie świadomość baskijskiego śladu w historii swej rodziny. Z kolei - co uznawane jest za zaskakujący fakt również w Hiszpanii - w samej Autonomii Kraju Basków najczęściej występują nazwiska hiszpańskie, a nie baskijskie, na co jednoznacznie wskazują dane statystyczne na temat częstotliwości nazwisk w poszczególnych prowincjach według dwóch kryteriów, a mianowicie: miejsca zamieszkania [INE 2013 a] oraz urodzenia [INE 2013 b] ${ }^{13}$.

Trzeba dodać, że za istotny przymiot związany z baskijskością tradycyjnie uważany jest katolicyzm. De facto, różny jest poziom nasilenia wiary w poszczególnych regionach, z jej silną wciąż pozycją między innymi wśród Basków. Nie jest to jednak w żadnym razie odróżniający element. Patrząc na całą Hiszpanię, katolicyzm był tam i w dalszym ciągu - mimo sekularyzacji, stanowi religię o charakterze większościowym. Również nie determinuje baskijskości - szeroko określając - komponent biologiczny. Choć prowadzone są badania genetyczne nad specyfiką DNA Basków i istnieją pewne cechy genetyczne o większej częstotliwości wśród tej grupy etnicznej, w zakresie tego, co obserwowalne na co dzień - tj. w zakresie fenotypów - nie są oni w sposób widoczny odmienni od mieszkańców sąsiednich regionów, tak samo jak choćby Kaszubi w Polsce. Współcześnie, w przeciwieństwie do czasów dawnych, nie ma nawet mowy o odzieniu, które pozwalałoby na odróżnienie członków poszczególnych wspólnot, poza strojem odświętnym czy też symbolicznej dystynkcji przez charakterystyczne dla tej etni emblematy. Pozostały jedynie wyobrażenia na ich temat z przeszłości oraz „typowe” elementy odzieży, takie jak txapela, tj. baskijski beret ${ }^{14}$, który wobec globalnej unifikacji codziennej mody uległ folkloryzacji. Rozpowszechniony już w XVII w., początkowo w Guipúzcoa i Nawarze [Gatti i in. 2005: 21], jako charakterystyczny dla ówczesnego regionalnego odzienia został z czasem za-

12 Więcej na temat migracji oraz innych istotnych procesów demograficznych w kontekście baskijskim patrz: Martín i Seguel [2005: 30 i nast.], Luxán [2005].

13 Problematykę nazwisk i imion, ich konstrukcji oraz możliwości wyboru w kontekście odradzania się tożsamości baskijskiej po transformacji systemowej w Hiszpanii, a także związków z polityką językową na poziomie ogólnokrajowym oraz Autonomii Kraju Basków przeznaczam na temat kolejnego artykułu.

14 Nazywany też opisowo w języku kastylijskim jako la boina vasca, co literalnie znaczy właśnie baskijski beret. Pod tą nazwą znany jest przez ogół Hiszpanów. 
adoptowany jako element munduru policji Autonomii Kraju Basków ${ }^{15}$. Nie jest to element aż tak odmienny zważywszy, że beret w różnych odmianach występuje jako tradycyjne nakrycie głowy wśród ludności cywilnej w różnych krajach oraz $\mathrm{w}$ formacjach militarnych i paramilitarnych na całym świecie. Beret - w zasadzie powszechny nie tylko w Autonomii Kraju Basków, ale również w innych regionach kraju, w tym Nawarze czy Kantabrii, jest na co dzień noszony przez mężczyzn starszego pokolenia oraz stanowi dziś popularną pamiątkę regionalną. Zwłaszcza w okresie świąt i sezonowych jarmarków, bywa noszony na ulicach baskijskich miast przez turystów z całego świata, w tym choćby Amerykanów czy Nowozelandczyków. Poza sklepami i stoiskami, można go łatwo kupić w sklepach internetowych, również z aplikacjami w postaci herbów poszczególnych prowincji, miejskich tarczy herbowych, w tym Bilbao, San Sebastian, Vitorii-Gasteiz, czy też baskijskiej flagi ikurriña $\mathrm{w}$ różnych wariantach, również $\mathrm{w}$ połączeniu $\mathrm{z}$ katalońskimi flagami senyera, co ma symbolizować wspólny front przeciw centralistycznej Hiszpanii. Choć w rzeczy samej beret może stanowić manifestację baskijskiej tożsamości, umiłowanie tradycji, a również poparcie dla secesji, w żadnym razie nie świadczy o przynależności do wspólnoty. Jego noszenie - à rebours - spełniać może funkcję prześmiewczą jako „udawanie Baska”, względnie jako traktowane z przymrużeniem oka stylizowanie się. Tym bardziej istotna jest rola euskera jako papierka lakmusowego uwiarygodniający baskijskość, mocującego bycie człowieka w świecie jako Baska i podtrzymującego poczucie wspólnoty.

\section{Zakończenie}

Język baskijski, nie tylko jako narzędzie komunikacji, ale i odzwierciedlenie tożsamości związanej z ziemią przodków oraz przywiązania do ich dziedzictwa, ma dla tkanki społecznej regionu znaczenie wyjątkowe. Mimo utożsamiania w euskera faktu znajomości języka z przynależnością do wspól-

15 Autonomia Kraju Basków ma od czasów wkrótce po transformacji systemowej, to jest od roku 1982 własną policję, tzw. policję autonomiczną o baskijskiej nazwie własnej Ertzaintza. Założona została w ślad za tradycją sprzed czasów frankizmu i istnieje zgodnie z art. 17 Statutu Autonomii Kraju Basków [Ley Orgánica 3/1979]. Na mocy precyzującej jej działalność ustawy o Policji w Kraju Basków z dnia 17 lipca 1992 r. [Ley 4/1992 de 17 de julio, de Policía del País Vasco] z późniejszymi poprawkami posiada pełne kompetencje w zakresie porządku publicznego, bezpieczeństwa obywateli, ruchu ulicznego oraz zabaw i widowisk publicznych. Posiada też częściowe kompetencje w zakresie m.in. walki z terroryzmem oraz działalności dochodzeniowej. 
noty etnicznej, nie wszyscy Baskowie go znają. To samo dotyczy kwestii tożsamości baskijskiej wśród mieszkańców Autonomii. Choć znaczący odsetek czuje się jednoznacznie i wyłącznie Baskami, a nie Hiszpanami, istnieje też niemały odsetek tych, dla których tożsamość baskijska jest komplementarna względem hiszpańskiej - co poddaję analizie i podejmuję próbę wyjaśnienia w odrębnym artykule. Interesujące byłoby przeprowadzenie badań łączących tożsamość oraz znajomość euskera na poziomie indywidualnym, a także sprawdzenie zależności statystycznych w populacji.

Co warto podkreślić, $\mathrm{w}$ przypadku Basków język ma zdecydowanie większe znaczenie $\mathrm{w}$ definiowaniu tożsamości niż fakt zamieszkiwania na terytorium historycznej krainy Baskonii i przywiązanie do jej terenów od pokoleń. Mniejsze znaczenie tego drugiego czynnika wynika z tego, że przynależne do dwóch państw i przecięte ich granicą obszary są trwałym przedmiotem sporu, a związek z ziemią ma nie tylko charakter sentymentu, ale jest też wyrazem pragmatycznych interesów i podlega prawom własności. Czy to Baskowie, Hiszpanie czy Francuzi - zajmowane tereny traktują jako swoje. Elementy terytorialne, tj. zarys Baskonii, tym bardziej jeśli dodatkowo naniesie się nań zakłócającą go formalną granicę między państwami, nie stanowią wiernego odwzorowania lokalnych tożsamości.

\section{Literatura cytowana:}

Amorrortu, Estibaliz (2003), Basque Sociolinguistics. Language, Society, and Culture. Reno, Nevada, University of Nevada Press, Center for Basque Studies.

Anderson, Benedict (1997), Wspólnoty wyobrażone: rozważania o źródłach i rozprzestrzenianiu się nacjonalizmu, tłum. Stefan Amsterdamski, Kraków, Instytut Wydawniczy Znak.

Azurmendi, Maria Josi, Bachoc Erramon, Zabaleta, Francisca (2001), Reversing language shift. The case of Basque, (w:) Joshua A. Fishman (red.), Can Threatened Languages be Saved? Reversing Language Shift Revisited. A $21^{\text {st }}$ Century Perspective. Clevedon/Tonawanda, NY/North York, Ontario, Multilingual Matters Ltd: 234-259.

Berger, Peter L., Luckmann, Thomas (2010), Społeczne tworzenie rzeczywistości. Traktat o socjologii wiedzy, tłum. Józef Niżnik, Warszawa, Wydawnictwo Naukowe PWN.

Biernacka, Maja (2009) La hispanidad. Idea prymatu narodu hiszpańskiego, „Studia Socjologiczne", nr 3 (194): 109-134.

Bokszański, Zbigniew i in. /Bokszański Zbigniew, Piotrowski Andrzej, Ziółkowski, Marek (1977), Socjologia jezzka, Warszawa, Wiedza Powszechna. 
Bucholtz, Mary, Hall, Kira (2004), Language and identity, (w:) Alessandro Duranti (red.). A Companion to Linguistic Anthropology, roz. 16, Oxford, The Blackwell Companions to Anthropology, Blackwell Publishing Ltd: 369-394.

Bucholtz, Mary, Hall, Kira (2010), Locating identity in language, (w:) Llamas, Carmen, Watt, Dominic (red.), Language and Identities, Edinburgh, Edinburgh University Press Ltd: 18-28.

Bugajski, Marian (2007), Język w komunikowaniu, Warszawa, Wydawnictwo Naukowe PWN.

Conversi, Daniele (1997), The Basques, the Catalans and Spain. Alternative Routes to Nationalist Mobilisation, Ethnonationalism in Comparative Perspective Series, Reno, Nevada, University of Nevada Press.

Durkheim, Émile (2000 [1895]), Zasady metody socjologicznej, tłum. Jerzy Szacki, Warszawa, Państwowe Wydawnictwo Naukowe.

Echeverria, Begoña (2007), Learning and working in Basque. Implications for Basque identity, (w:) Katherine Schuster, David Witkosky (red.), Languages of the Land. Policy, Politics, Identity. A Volume in Studies in the History of Education, roz. 10, Charlotte NC, Information Age Publishing Inc: 197-194.

Fishbane, Simcha (1995), Back to the yeshiva. The social dynamics of an orthodox Sabbath morning service, (w:) Jack L. Lightstone, Frederick B.Bird i in. (red.), Ritual and Ethnic Identity. A Comparative Study of the Social Meaning in Liturgical Ritual in Synagogues, Waterloo, Ontario, Wilfrid Lauriel University Press: 123-134.

Gatti, Gabriel (2007), Identidades débiles. Una propuesta teórica aplicada al estudio de la identidad en el País Vasco, Collección Monografías, Madryt, Centro de Investigaciones Sociológicas, maj, nr 237.

Gatti, Gabriel i in. /Gatti, Gabriel, Irazuzta, Ignacio, Martínez de Albeniz, Iñaki (2005), Introduction, (w:) Gabriel Gatti, Ignacio Irazuzta, Iñaki Martínez de Albeniz (red.), Basque Society. Structures, Institutions, and Contemporary Life, Reno, Nevada, University of Nevada Press: 7-25.

Głuszkowski, Michał (2013), Socjologia w badaniach dwujęzyczności, Toruń, Wydawnictwo Naukowe Uniwersytetu Mikołaja Kopernika.

Gorka, Aulestia, White, Linda (1992), Basque-English, English-Basque Dictionary, Reno, Nevada, University of Nevada Press.

Haasse, Martin (2011), Basque, (w:) Bernd Kortmann, Johan van den Auwera (red.), The Languages and Linguistics of Europe. A Comprehensive Guide, Boston/Berlin, Walter de Gruyter GmbH and Co. KG: 209-222.

Handke, Kwiryna (2009), Socjologia jezyka, Warszawa, Wydawnictwo Naukowe PWN.

Hualde, José Ignacio, Ortiz de Urbina, Jon (praca zbiorowa), (2003), A Grammar of Basque, Berlin, Mouton de Gruyter, Walter de Gruyter GmbH and Co. KG.

Ibarretxe, Gozton, Larrea, Kepa (2012), Basque diction, (w:) Duane Richard Karna (red.), The Use of the International Phonetic Alphabet in the Choral Rehearsal, Plymouth, The Rowman \& Littlefield Publishing Group, Scarecrow Press Inc: 179-188.

Johnstone, Barbara (2010), Locating language in identity, (w:) Llamas, Carmen, Watt, Dominic (red.), Language and Identities, Edinburgh, Edinburgh University Press Ltd: 29-38. 
Kasmir, Sharryn (1996), The Myth of Mondragón. Cooperatives, Politics, and Working-class Life in a Basque Town, Albany NY, State University of New York Press.

King, Alan Roy (1994), The Basque Language, A Practical Introduction, Reno, Nevada, University of Nevada Press.

Klappoth, Danièlle M. (2004), Narrative as Social Practice. Anglo-Western and Australian Aboriginal Oral Traditions, Berlin, Walter de Gruyter Gmbh \& Co., KG.

Koseła, Krzysztof (2003), Polak i katolik. Splątana tożsamość, Warszawa, Wydawnictwo Instytutu Filozofii i Socjologii Polskiej Akademii Nauk.

Lévi-Strauss, Claude (2011 [1958]), Antropologia strukturalna, tłum. Krzysztof Pomian, Warszawa, Wydawnictwo Aletheia.

Luxán, Marta (2005), Demographic growth and migration, (w:) Gabriel Gatti, Ignacio Irazuzta, Iñaki Martínez de Albeniz (red.), Basque Society. Structures, Institutions, and Contemporary Life, roz. 3, Reno, Nevada, University of Nevada Press: 58-73.

Mallea-Olaetxe, Joxe (2000), Speaking through the Aspens. Basque Tree Carvings in Nevada and California, The Basque Series, Reno, Nevada, University of Nevada Press.

Martín, Idoia, Seguel, Andrés G. (2005), Structures. Socioeconomic, territorial, urban, (w:) Gabriel Gatti, Ignacio Irazuzta, Iñaki Martínez de Albeniz (red.), Basque Society. Structures, Institutions, and Contemporary Life, roz. 1, Reno, Nevada, University of Nevada Press: 26-45.

Mathy, Jean-Phillippe (1997), Del regionalismo a la etnicidad. Identidad vasca y migraciones a Estados Unidos, (w:) Xavier F. Medina (red.), Los otros vascos. Las migraciones vascas en el XX siglo, Madryt, Editorial Fundamentos: 77-104.

Mauss, Marcel (2001 [1950]), Socjologia i antropologia, tłum. Marcin Król, Warszawa, Wydawnictwo Naukowe KR.

Mitxelena, Koldo (2001) Entre Nosotros. Itxaropena, Irun, ALBERDANIA, S.L/Diputación Foral de Guipúzcoa.

Sapir, Edward (1978), Kultura, język, osobowość, tłum. Roman Zimand, Barbara Stanosz, Warszawa, Państwowy Instytut Wydawniczy.

Schütz, Alfred (2012), O wielości światów. Szkice z socjologii fenomenologicznej, tłum. Barbara Jabłońska, ze wstępem do wyd. polskiego Krzysztofa Tomasza Koneckiego i Marka Gorzko, Kraków: Zakład Wydawniczy NOMOS.

Taylor, Charles (1996), Etyka autentyczności, seria Demokracja, filozofia i praktyka, tłum. Andrzej Pawelec, Kraków, Zakład Wydawniczy Znak.

Tazbir, Janusz (2011), Język polski a tożsamość narodowa. „Nauka”, nr 2: 7-16.

Trask, Robert Lawrence (1997), The History of Basque. Londyn/Nowy Jork, Routledge.

Turner, John C. (1982) Towards a cognitive redefinition of the social group, (w:) Henri Tajfel, Social Identity and Intergroup Relations, Cambridge, Cambridge University Press: 15-39.

Waldman, Carl, Mason, Catherine (2006), Encyclopedia of European Peoples, Nowy Jork, Facts on File Inc., Infobase Publishing.

Whorf, Benjamin Lee (2002 [1956]), Język, myśl i rzeczywistość, tłum. Teresa Hołówka, Warszawa, Wydawnictwo KR.

Zallo, Ramón (2006), Basques, Today. Culture, History and Society in the Age of Diversity and Knowledge, ze wstępem Armanda Mattellarta, Irun, ALBERDANIA S.L. 


\section{Inne źródła:}

ES 2008/ IV Encuesta Sociolingüística 2006, raport z badań, Departamento de Cultura, Servicio Central de Publicaciones de Gobierno Vasco, Vitoria-Gasteiz (17.05.2016) ES 2013/ V Encuesta Sociolingüística 2011, raport z badań, Departamento de Educación, Política Lingüística y Cultura, Servicio Central de Publicaciones de Gobierno Vasco, Vitoria-Gasteiz (17.05.2016)

Ley Orgánica 3/1979, de 18 de diciembre, de Estatuto de Autonomía para el País Vasco, Boletín de Estado núm. 306, de 22 de diciembre de 1979, Referencia: BOE -A-1979-30177/ Ustawa 3/1979, z 18 grudnia, o Statucie Autonomii Kraju Basków, Dziennik Ustaw nr 306, z 22 grudnia 1979 roku, nr ref. BOE-A-1979-30177, pełen tekst statutu (pdf):

https://www.boe.es/buscar/pdf/1979/BOE-A-1979-30177-consolidado.pdf (17.05.2016)

Euskobarómetro, Estudio periódico de la opinion pública vasca, maj 2012, Raport z badań pod kierownictwem Francisco José Llera Ramo, Euskal Herriko Unibertsitatea/Uniwersytet Kraju Basków, s. 1-76 (09.04.2016)

Euskobarómetro, Estudio periódico de la opinion pública vasca, maj 2013, Raport z badań pod kierownictwem Francisco José Llera Ramo, Euskal Herriko Unibertsitatea/Uniwersytet Kraju Basków, s. 1-76 (16.04.2016)

Euskobarómetro, Estudio periódico de la opinion pública vasca, maj 2014, Raport z badań pod kierownictwem Francisco José Llera Ramo, Euskal Herriko Unibertsitatea/Uniwersytet Kraju Basków, s. 1-73 (20.04.2016)

Euskobarómetro, Estudio periódico de la opinion pública vasca, maj 2015, Raport z badań pod kierownictwem Francisco José Llera Ramo, Euskal Herriko Unibertsitatea/Uniwersytet Kraju Basków, s. 1-72 (17.10.2016)

Euskobarómetro, Estudio periódico de la opinion pública vasca, styczeń 2016, Raport z badań pod kierownictwem Francisco José Llera Ramo, Euskal Herriko Unibertsitatea/Uniwersytet Kraju Basków, s. 1-77 (17.08.2016)

Instituto Nacional de Estadística (INE 2013a)/Narodowy Instytut Statystyczny, Datos procedentes de la Estadística del Padrón Continuo a 1 de enero de 2013, Hoja 2, Primer apellido por provincia de residencia. Apellidos más frequentes por provincia de residencia/ Arkusz 2. Pierwsze nazwisko według prowincji zamieszkania. Najczęstsze nazwiska według prowincji zamieszkania, zestawienie tabelaryczne danych na dzień 1 stycznia 2013 roku, opublikowane przez INE 22 maja 2014 roku, dostępne na stronie internetowej INE pod adresem: http:/www.ine.es/daco/daco42/nombyapel/nombyapel.htm (17.05.2016)

Instituto Nacional de Estadística (INE 2013b)/Narodowy Instytut Statystyczny, Datos procedentes de la Estadística del Padrón Continuo a 1 de enero de 2013, Hoja 3. Primer apellido por provincia de nacimiento. Apellidos más frequentes por provincia de nacimiento/ Arkusz 3. Pierwsze nazwisko według prowincji urodzenia. Najczęstsze nazwiska według prowincji urodzenia, zestawienie tabelaryczne danych na dzień 1 stycznia 2013 roku, opublikowane przez INE 22 maja 2014 r., dostępne na stronie internetowej INE pod adresem: http:/www.ine.es/daco/daco42/nombyapel/nombyapel.htm (10.04.2016) 
Ley Orgánica 3/1979/Estatuto de Autonomía del País Vasco/ Statut Autonomii Kraju Basków (nazywany również Estatuto de Guernica [bask. Gernica]/Statut z Guerniki) z 24 października 1979 roku, przyjęty 18 grudnia 1979 roku, dokument dostępny on-line na oficjalnej stronie internetowej Parlamentu Autonomii Kraju Basków: Eusko Legebiltzarra/Parlamento Vasco, link do strony: http://www.parlamento. euskadi.net/c_estatuto_0_0.html (12.04.2016)

Ley 4/1992 de 17 de julio, de Policía del País Vasco/Ustawa 4/1992 o Policji w Kraju Basków z dnia 17 lipca 1992 roku z późniejszymi poprawkami, opublikowana w BOPV pod numerem $155 \mathrm{w}$ dniu 11 sierpnia 1992 roku oraz po poprawkach w BOE pod numerem $39 \mathrm{w}$ dniu 15 lutego 2012 roku, wersja po poprawkach ma moc prawną od dnia 7 lipca 2012 roku, dokument dostępny on-line na stronie internetowej: http:// noticias.juridicas.com/base_datos/CCAA/pv-14-1992.html (17.05.2016) 


\section{StreszCZENIE}

Artykuł poświęcony jest językowi baskijskiemu, którego własną nazwą jest euskera, nie w kategoriach lingwistycznych, ale życia społecznego w kontekście należącej do państwa hiszpańskiego Autonomii Kraju Basków. Jest to endemiczny język, który nie należy do grupy języków romańskich, ani nawet indoeuropejskich i w przeciwieństwie do pozostałych języków mniejszościowych pozostaje w Hiszpanii całkowicie niezrozumiały dla tych, którzy się go nie uczyli. Wobec zawodności pozostałych świadectw tożsamości, takich jak baskijskie nazwiska czy przywiązanie do ziemi, umiejętność sprawnego posługiwania się euskera stanowi podstawowy wyróżnik symboliczny baskijskiej tożsamości oraz sposób na jej uwiarygodnienie wśród pobratymców. W tradycji tego języka ma miejsce konflacja znaczeniowa dotycząca pojęcia euskaldunak, które odnosi się zarówno do Basków, jak i osób posługujących się euskera. Jak pokazuje artykuł, fakt ten stanowi nie tylko o jego kardynalnym znaczeniu dla baskijskości, podtrzymaniu jej we wspólnocie i rozpoznania swoich od obcych, ale nawet utożsamianiu znajomości euskera z przynależnością do baskijskiej wspólnoty etnicznej.

\section{Słowa kluczowe:}

Baskowie, język, tożsamość, Hiszpania, wspólnota języka, euskera/euskaral eskuara/eskuora/üskara.

\section{SUMMARY}

The article is dedicated to euskera, i.e. the native language spoken by the Basques. The major focus is not on its linguistic but social aspects in the context of the Basque Autonomous Community which forms a part of the Spanish state. It is an endemic language which does not belong to the Romance languages and not even to Indo-European language group. As opposed to other minority languages in Spain, it is completely incomprehensible in Spain to the ones who have not studied it. Due to fallibility of other indicators of identity, such as Basque names or being attached to the fatherland, the ability to communicate effectively in euskera constitutes a fundamental symbolic marker of identity and provides the way to prove it to the Basque compatriots. In this language tradition there is a conflation of meaning concerning the term euskaldunak, referred both to Basques and individuals who display the ability to speak euskera. The article shows that this language is not only cardinal when it comes to Basqueness, preserving it in the 
community and distinguishing us from them, but even equating linguistic capacity with belonging to the Basque ethnic group.

\section{Keywords:}

Basques, language, identity, Spain, language community, euskera/euskara/eskuara/ eskuora/üskara. 